\title{
PENGARUH MODEL PEMBELAJARAN LEARNING STARTS WITH A QUESTION (LSQ) BERBANTUKAN MEDIA PETA KONSEP TERHADAP HASIL BELAJAR SISWA PADA POKOK BAHASAN LARUTAN ELEKTROLIT DAN NON- ELEKTROLIT
}

\section{THE INFLUENCE OF LEARNING STARTS WITH A QUESTION (LSQ) LEARNING MODELS ES TO HELP MEDIA CONCEPT MAPS ON STUDENT LEARNING OUTCOMES IN THE TOPICS OF THE DISCUSSION OF ELECTROLITE AND NON-ELECTROLITE SOLUTIONS}

\author{
Listiani $^{1}$, Muhammad Amir M. ${ }^{2 *}$. Hartati ${ }^{1}$ \\ ${ }^{I}$ Program Studi Sarjana Pendidikan Kimia, Fakultas Keguruan dan Ilmu Pendidikan, Universitas Mulawarman, \\ Samarinda, Indonesia \\ ${ }^{2}$ Program Studi Pascasarjana Pendidikan Kimia, Fakultas Keguruan dan Ilmu Pendidikan, Universitas \\ Mulawarman, Samarinda, Indonesia \\ *Corresponding Author : nurergaamir@yahoo.com
}

\begin{abstract}
ABSTRAK
Penelitian ini bertujuan untuk mengetahui pengaruh penggunaan model Learning Starts With A Question (LSQ) berbantukan media peta konsep terhadap hasil belajar siswa kelas X SMA Negeri 14 Samarinda pada pokok bahasan larutan elektrolit dan non-elektrolit. Jenis penelitian ini adalah penelitian eksperimen yang dilakukan dalam tiga kali pertemuan. Populasi dalam penelitian ini adalah seluruh siswa kelas X SMA Negeri 14 Samarinda. Sampel penelitian yang diambil adalah kelas X-2 dan X-3 dengan masing-masing kelas berjumlah 30 orang. Teknik pengambilan sampel ini menggunakan teknik purposive sampling. Kelas X-2 menggunakana model pembelajaran LSQ berbantukan media peta konsep sedangkan kelas X-3 menggunakan model pembelajaran langsung. Teknik pengumpulan data dalam penelitian ini menggunakan teknik tes dan dokumentasi. Teknik analisis data menggunakan uji t. Berdasarkan hasil pengolahan data, diperoleh nilai rata-rata kelas X-2 dan X-3 adalah berturut-turut adalah 79,93 dan 74,60. Kelas yang menggunakan model pembelajaran LSQ berbantukan media peta konsep memiliki rata-rata nilai hasil belajar lebih tinggi daripada rata-rata nilai hasil belajar kelas yang menggunakan model pembelajaran langsung. Berdasarkan teknik analisa data menggunakan uji t pada taraf signifikan 5\% diperoleh kesimpulan bahwa terdapat pengaruh penggunaan model pembelajaran LSQ berbantukan media peta konsep terhadap hasil belajar siswa pada pokok bahasan larutan elektrolit dan non-elektrolit.
\end{abstract}

Kata kunci : $L S Q$, peta konsep, hasil belajar, elektrolit dan non-elektrolit

\begin{abstract}
This study aimed to determine the effect of implementation of make a match learning model in team games tournament (TGT) learning model on senior high school student's learning outcome of compound nomenclature. This research was classified as quasi experiment. This research was conducted at SMA N 5 Samarinda, Kalimantan Timur, Indonesia. Subject of research was students tenth grade of natural science 1 (experimental group, 32 students) and students tenth grade of natural science 2 (control group, 31 students) which was selected using purposive sampling technique. The learning model implemented in the experimental group was make a match learning model in TGT learning model and the learning model implemented in control group was the TGT learning model. There were three data used in this research i.e. (1) documentation data which were students learning outcome before experiments, (2) student's cognitive ability test that obtained from $25 \%$ of $1^{\text {st }}$ post test score, $25 \%$ of $2^{\text {nd }}$ post test score and
\end{abstract}


$50 \%$ chapter examination score, and (2) student activity data that obtained by observation. Result of this research showed that the implementation of make a match learning model in TGT learning model effect the senior high school student's learning outcome of compound nomenclature.

\section{Keywords: $L S Q$, concepts maps, learning outcomes, electrolytes and non-electrolytes.}

\section{PENDAHULUAN}

Keaktifan siswa dalam pembelajaran kimia salah satunya dapat dipengaruhi oleh penggunaan model pembelajaran. Guru harus mampu memilih model pembelajaran yang tepat dan sesuai dengan tujuan tertentu, materi yang akan dibelajarkan dan kondisi siswanya. Salah satu model pembelajaran yang dapat mengkondisikan siswa untuk mampu menanggapi pelajaran kimia secara aktif yaitu model pembelajaran Learning Starts With A Question (LSQ).

Model pembelajaran LSQ merupakan salah satu model pembelajaran yang mampu membuat siswa lebih aktif dalam pembelajaran di kelas (Silberman, 2003). Model learning start with a question adalah suatu model pembelajaran aktif dalam bertanya. Agar siswa aktfi dalam bertanya, maka siswa diminta untuk membaca terlebih dahulu. Dengan membaca, maka siswa memiliki gambaran tentang materi yang akan dipelajari sehingga apabila dalam membaca atau membahas materi tersebut terjadi kesalahan konsep akan terlihat dan dapat dibahas serta dibenarkan secara bersama-sama. Adapun langkah-langkah dari model pembelajaran LSQ adalah (1) Menentukan dan membagikan materi yang akan dipelajari, (2) Meminta kepada siswa untuk mempelajari materi bersama teman sebangkunya, (3) Meminta kepada siswa untuk memberikan tanda pada bagian yang tidak dipahami, dan membahas poin-poin yang telah diberi tanda, (4) Membagi kelas menjadi beberapa kelompok yang beranggotakan 4 sampai 5 orang, (5) Meminta siswa untuk mendiskusikan pertanyaan yang akan ditulis mengenai materi yang telah dibaca, (6) Mengumpulkan pertanyaanpertanyaan yang telah ditulis oleh siswa, dan (7) Menyampaikan materi pelajaran dengan menjawab pertanyaan-pertanyaan yang dibuat siswa.

Beberapa penelitian dengan menggunakan model pembelajaran LSQ telah dilakukan dan dapat meningkatkan hasil belajar siswa (Susatyo, 2013; Mutmainnah \& Nono, 2016). Model pembelajaran LSQ juga dapat meningkatkan pemahaman matematis siswa (Otrina, 2012). Bahkan berdasarkan hasil penelitian, diperoleh hasil bahwa hasil belajar fisika siswa yang diajar dengan menggunakan media pembelajaran LSQ lebih tinggi daripada hasil belajar siswa yang diajar menggunakan model pembelajara A Question Student Have (QSH) (Oktafia, Wayong, \& Jusriana, 2018).

Model pembelajaran LSQ ini akan lebih maksimal jika dikombinasikan dengan penggunaan media pembelajaran yang dapat membantu siswa untuk melihat keterkaitan atau hubungan antara konsep satu dengan konsep yang lainnya pada pokok bahasan larutan elektrolit dan non-elektrolit yaitu dengan menggunakan media peta konsep. Peta konsep dapat meningkatkan daya ingat siswa dalam belajar. Artinya siswa dengan cepat mendapatkan pengetahuan yang lebih efektif dan efisien dengan berpikir reduktif yaitu dengan cara merangkum informasi yang banyak kedalam konsep-konsep utama yang saling berhubungan ke dalam sebuah diagram atau gambar dan mencakup keseluruhan konsep-konsep yang dipelajari (Ismail, 2011).

Pada model pembelajaran ini, peneliti mengambil pokok bahasan larutan elektrolit dan non-elektrolit yang hampir secara keseluruhan berisi teori yang biasanya cukup membosankan bagi siswa. Atas dasar ilmiah maka dituntut kemampuan dan keterampilan seorang guru untuk mampu menciptakan suatu pembelajaran yang sesuai dengan kondisi siswa dan konsep karakterisitik ilmu kimia yang dibelajarkan. Model pembelajaran LSQ berbantukan media peta konsep ini menstimulasi siswa untuk bertanya yang merupakan kunci dalam belajar sehingga hasil belajar siswa akan meningkat sesuai dengan yang diharapkan.

Berdasarkan uraian di atas, maka penulis tertarik untuk melaksanakan suatu penelitian yang berkaitan dengan model pembelajaran LSQ berbantukan media peta konsep terhadap hasil belajar siswa pada pokok bahasan larutan elektrolit dan non-elektrolit kelas X SMAN 14 Samarinda.

\section{METODE PENELITIAN}


Penelitian ini dilaksanakan dalam tiga kali pertemuan. Pada pertemuan pertama hingga pertemuan kedua siswa mengenai materi larutan elektrolit dan non-elektrolit dengan model pembelajaran LSQ berbantukan media peta konsep. Pada akhir pertemuan pertama dan kedua ini diberikan postes. Pada pertemuan ketiga dilakukan ulangan harian.

Populasi dalam penelitian ini adalah seluruh siswa kelas X SMA Negeri 14 Samarinda. Sampel yang digunakan dalam penelitian ini sebanyak dua kelas yaitu kelas X-2 sebanyak 30 siswa belajar dengan menggunakan model pembelajarn LSQ berbantukan media peta konsep dan kelas X-3 sebanyak 30 siswa belajar dengan menggunakan model pembelajaran langsung. Pengambilan sampel dalam penelitian ini berdasarkan teknik purposive sampling.

Penelitian ini menggunakan teknik pengumpulan data dokumentasi dan teknik tes/ Teknik tes menggunakan postes dan ulangan harian. Dokumentasi berupa nilai ulangan harian pada bab sebelumya. Data postes dan ulangan harian diolah ditentukan skor dan nilai hasil belajarnya. Data yang diperoleh dianalisa menggunakan uji $\mathrm{t}$ untuk mengetahui apakah terdapat pengaruh atau tidak belajar menggunakan model pembelajaran LSQ berbantukan media peta konsep terhadap hasil belajar siswa.

\section{HASIL DAN PEMBAHASAN}

Berdasarkan hasil pengolahan data dimana kelas X-2 belajar dengan menggunakan model pembelajaran LSQ berbantukan media peta konsep dan X-3 belajar dengan menggunakan model pembelajaran langsung dapat dilihat pada Gambar 1.

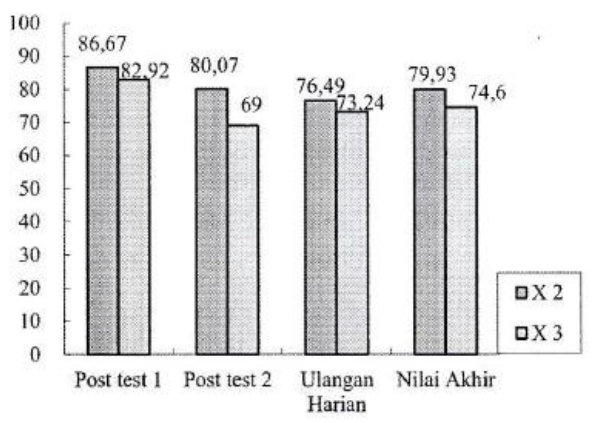

\section{Gambar 1. Hasil Belajar Siswa}

Berdasarkan Gambar 1. Terlihat bahwa ratarata nilai hasil belajar siswa yang menggunakan model pembelajaran LSQ berbantukan media peta konsep pada setiap pertemuan selalu lebih tinggi daripada rata-rata nilai hasil belajar siswa yang menggunakan model pembelajaran langsung. Hal ini dikarenakan adanya kelebihan-kelebihan pada model pembelajaran LSQ dengan berbantuan media peta konsep. Pembelajaran dengan model pembelajaran LSQ berbantukan media peta konsep memberikan kelebihan diantaranya adalah siswa lebih siap dalam memulai pelajaran, karena siswa telah terlebih dahulu belajar bahan bacaan sehingga mempunyai sedikit gambaran dan lebih paham setelah mendapat tambahan dari guru. Siswa belajar lebih aktif bertanya, karena memberikan kesempatan mengembangkan diri, fokus pada bahan bacaan atau materi ceramah. Siswa mampu menyelidiki materi pelajaran sendiri tanpa penjelasan terlebih dahulu dari guru.

Materi dapat diingat lebih lama oleh siswa. Kecerdasan siswa lebih diasah pada saat siswa belajar untuk mengajukan pertanyaan. Memperluas wawasan siswa melalui bertukar pendapat. Memberikan pengalaman belajar yang berbeda kepada siswa. Kegiatan bertanya dan menjawab yang dilakukan oleh guru dan siswa dalam proses belajar mengajar mampu menumbuhkan pengetahuan baru pada diri siswa, dengan demikian siswa harus diberikan ruang agar tidak hanya mendapatkan informasi saja, melainkan harus merangsang dan mengaktifkan siswa dalam bertanya sehingga meningkatkan pemahaman siswa dalam proses pembelajaran. Penerapan model pembelajaran LSQ dapat meningkatkan hasil belajar siswa yaitu dari $68 \%$ pada siklus I menjadi $87 \%$ pada siklus II. Penerapan model pembelajaran LSQ juga dapat meningkatkan aktivitas siswa yaitu dari $69 \%$ pada siklus I menjadi $82 \%$ pada siklus II (Syafura, 2014).

Adapun penggunaan media peta konsep dapat membantu siswa melihat makna materi pelajaran secara lebih luas dalam setiap komponen konsepkonsep dan mengenali kesalahan konsep (Mudjiono, 1991). Penggunaan media peta konsep juga dapat meningkatkan penguasaan konsep yang dimiliki siswa terhadap materi pelajaran.

Model pembelajara LSQ berbantukan media peta konsep juga memiliki kelemahan yaiut siswa yang minat membacanya rendah akan sulit mengikuti pelajaran karena awal pelajaran dimulai dengan membaca. Proses pembelajarannya 
membutuhkan waktu panjang jika banyak pertanyaan yang dilontarkan siswa. Sering terjadi kesulitan untuk menjaga agar siswa tetap tertarik dengan apa yang dipelajarinya. Untuk mengatasi kelemahan ini, guru dituntut untuk kreatif dalam membuat bahan bacaan yang menarik dan mudah dipahami siswa serta menjelaskan dimana letak pentingnya pertanyaan tersebut.

Secara keseluruhan, nilai rata-rata hasil belajar siswa pada kelas X-2 yang menggunakan model pembelajaran LSQ berbantukan media peta konsep yaitu 79,93, lebih tinggi dibandingkan kelas X-3 yang menggunakan model pembelajaran langsung yaitu 74,6. Setelah dianalisis dengan uji t, diperoleh $\mathrm{t}_{\text {hit }}=2,733$ sedangkan $\mathrm{t}_{\mathrm{tab}}=2,002$, sehingga diperoleh $t_{\text {hitung }}>t_{\text {tabel }}$ yaitu 2,733 $>2,002$ pada taraf signifikan $5 \%$ yang berarti bahwa $\mathrm{H}_{0}$ ditolak dan $\mathrm{H}_{\mathrm{a}}$ diterima berarti bahwa terdapat pengaruh penggunaan model pembelajaran LSQ berbantukan media peta konsep terhadap hasil belajar siswa pada pokok bahasan larutan elektrolit dan non-elektrolit di SMA Negeri 14 Samarinda.

Pengaruh positif yang diberikan oleh model LSQ berbantukan media peta konsep ini dikarenakan siswa lebih bersemangat dalam belajar. Pertanyaan yang lahir dari siswa setelah membaca akan mendorong rasa ingin tahu yang besar sehingga dapat memotivasi dan mengaktifkan siswa. Selain itu, media peta konsep yang digunakan dapat membantu guru meningkatkan efektivitas pengajaran.

\section{PENUTUP}

\section{Simpulan}

Berdasarkan hasil penelitian dan analisis data, dapat disimpulkan bahwa penggunaan model pembelajaran LSQ berbantukan media peta konsep mempengaruhi hasil belajar kimia siswa pada pokok bahasan larutan elektrolit dan non-elektrolit kelas X SMA Negeri 14 Samarinda. Hasil belajar siswa dengan menggunakan model pembelajaran LSQ berbantukan media peta konsep lebih baik dibandingkan dengan model pembelajaran langsung.

\section{Saran}

Saran untuk penelitian selanjutnya adalah perlunya memvariasi model pembelajaran yang lain dengan berbantuan media peta konsep.

\section{UCAPAN TERIMAKASIH}

Terimakasih kepada Kepala Sekolah, dewan guru, Ibu Masniah serta staf tata usaha serta siswasiswa SMA Negeri 14 Samarinda yang telah memberikan izin kepada penulis untuk melaksanakan penelitian

\section{DAFTAR PUSTAKA}

Ismail, M. (20XI). Meningkatkan Hasil Belajar Ikatan Kimia dengan Menerapkan Model Pembelajaran Peta Konsep pada Siswa Kelas X di SMA Negeri 1 Telaga. Gorontalo: FMIPA Universitas Negeri Gorontalo.

Mutmainnah, \& Nono. (2016). Penerapan Model Pembelajaran LSQ untuk Meningkatkan Keaktifan dan Hasil Belajar Ilmu Statistika bangun Program Keahlian TGB SMKN Binaan Provinsi Sumatera Utara. Jurnal Education Building, Vol. 2, No. 1, ISSN : 2477-4989, XI17.

Oktafia, Y., Wayong, M., \& Jusriana, A. (2018). Perbandingan Hasil Belajar Menggunakan Media Pembelajaran Learning Starts With A Question dengan A Question Student Have. Jurnal Pendidikan Fisika, Vol. 6, No. 1, ISSN 2355-5785.

Otrina, S. (2012). Penerapan Model Pembelajaran Aktif Tipe Learning Starts With A Question (LSQ) terhadap Pemahaman Konsep Matematis Siswa SMP Negeri 2 Pasaman. Padang: STKIP PGRI.

Silberman, M. L. (2003). Active Learning 101 Cara Belajar Siswa Aktif. Bandung: Nuansa Cendekia.

Susatyo, E. B. (2013). Penggunaan Model Learning Starts With A Question and Self Regulated Learning pada Pembelajaran Kimia. Malang: FKIP Matematika UNM.

Syafura, W. (2014). Penerapan Media Pembelajaran Pelajaran diimulai dengan Pertanyaan (Learning Starts With A Question) untuk Meningkatkan Aktivitas dan Hasil Belajar pada Kompetensi Ilmu Batu dan Beton SMK Negeri 2 Binjai Tahun Ajaran 2013/2014. Medan: Skripsi FT. UNIMED. 